\title{
Conversation, a New Paradigm for Librarianship?
}

\author{
Joan M. Bechtel
}

Criticized for their isolation from the central mission of the college or university and, at the same time, struggling to accommodate the tremendous growth of information and technology, academic librarians need a new paradigm for library service that will effectively direct and inform planning for the future. Conversation, crucial for human life in society and intrinsic to the nature of libraries, may well be the appropriate model for providing the guidance, means, and context for change in academic librarianship.

hat these are challenging, often difficult, times for academic libraries is no news to anyone in the library world. Concern for professionalism, with its attention to accountability and responsibility, abounds. Unprecedented growth in technology provides vast new opportunities for communication, and the availability of information far outstrips most people's capacity to digest it all. In the face of this information explosion, it is ironic that academic librarians are casting about for an appropriate myth or model for library service. Witness the ACRL Third National Conference (April 4-7, 1984), called to address the issue of the present and future direction of academic libraries. While several of the participants in that conference called for a new paradigm for librarianship or suggested possibilities in the search for one, a compelling new image for trenchant library service was not found. While critics charge that academic libraries are not sufficiently integrated into the central concerns of the college or university and that librarians have their own, independent agendas, librarians responsible for present services as well as plans for the future are uneasy. Perhaps it is an overstatement to say that academic librarians are drifting in a vast sea of information and technological advances, searching for an appropriate course of action. Neverthe- less, we appear to have lost the stabilizing rudder of confidence in who we are and what we are to do. As a more powerful alternative to the images of librarianship already available or proposed, I suggest that we begin to think of libraries as centers for conversation and of ourselves as mediators of and participants in the conversations of the world.

\section{OLD IMAGES}

Libraries in the past have been labeled "The heart of the college or university," "the center of our intellectual life," "warehouse for storing books." If the "heart of the college" cliché is correct, heaven help the educational world; the library functioning as the heart of the college works about as well as the Jarvic 7 . Fortunately, however, for the colleges and universities of the land, the library never was the "heart of the college," and today the claim is little more than sentimental garbage trotted out by presidents and deans when they are required to say something flattering about libraries; neither the speaker nor the hearers believe it. As a paradigm for library service it provides no clues to the services needed in the university, nor does it help to clarify the role of librarians in the educational process.

The characterization of libraries as the "center of our intellectual life" is not

Joan M. Bechtel is a librarian at Dickinson College, Carlisle, Pennsylvania 17013. 
much better because that center is often elsewhere, in a group of scholars working on a problem, in a laboratory where the professor and students are testing a hypothesis, in a group of friends who meet regularly for study and discussion, in a classroom, or even in a student's room or a faculty member's office as he or she reads, thinks, and writes. ${ }^{2}$

In the university or college, libraries are more often viewed, one suspects, as warehouses for the storage of books and other materials, rather than hearts or centers of intellectual activity. And as storehouses, dusty places that one occasionally visits to recover some bit or piece that is useful, they require little more than custodial care. As such, they are not often regarded as a top priority in academic institutions, much less as central to the life of the mind and the educational process. While few librarians would accept the warehouse image, many view their libraries as their particular province. In the warehouse imagery, there clearly is no guide for dynamic library service.

\section{THE BUSINESS MODEL}

In order to reconceptualize librarianship for an uncertain future and in the hope of finding a new image, Kaye Gapen suggested using Mary Parker Follet's "Law of the Situation" question: "What business are we really in? ${ }^{\prime \prime 3}$ Her response was that libraries have been in the package (book) delivery business. In the future, she says, libraries will be in the information delivery business, a change that will radically alter what librarians do. While the notion of information delivery rather than package delivery serves to enlarge the possible content of that which is delivered and points to the use of modern technologies, it does not indicate a more active role for librarians either in seeking to serve new clientele or in serving present users better, nor does it force librarians into the center of the critical-thinking processes of the university.

Both the question, "What business?" and the answer, "Information delivery," smack of mail-order houses, consumerism, profit, efficiency, and popular culture. They make librarians delivery boys or Purolator truck drivers or Federal Express administrators. They transform library users into consumers and books and information into commodities to be used and discarded. All become part of the consumer, disposable society. The result is that the institution that ought to resist the dehumanizing, competitive, degrading aspects of modern culture has ended up adopting the corporate world as its guru. Criticism of the profit-and-loss orientation, of efficiency as a primary value, and of an ends-directed stance is muted or cut off.

Given the business orientation of our culture, it is not surprising that libraries are tempted to look at the corporate model in the search for an energizing, rejuvenating image. Appropriating a new image of librarianship from the world of commerce, however, will only serve, as Parson says, to "fix the limits of the possible. ${ }^{\prime 4}$ Conceiving of the business of libraries as information delivery will do nothing to redirect. librarians' "strict identification with the library as an agency or institution to an identification with the client or library user $^{\prime \prime}$ because the focus of the business world is on its own survival, not on the enhancement of the quality of life. Furthermore, the business model encourages continuing the old pattern of making the delivery in response to a patron request. The burden for initiating the request, knowing what to ask for, and evaluating the information provided all rests with the patron or, at best, depends upon the library's effectiveness in marketing the products and services it chooses. What remains as highest priority is improving the efficiency of the delivery system rather than seeking to understand and meet the needs of the library user.

\section{MISSION AND GOALS}

Having no controlling paradigm for guidance and seeking to improve library service, librarians in the last ten years or so have placed greater and greater emphasis upon the need to articulate a clear statement of mission and goals. These often relate to regularly updated, long-range plans. Surely these are needed; no library can function responsibly without them. 
The problem, however, is in identifying the library with its mission and goals rather than looking for its intrinsic being or value.

The difficulty with goals is that they are rigid, resistant to change, often selflimiting, and that they focus on the achievements of the person or group articulating the goals-a focus that is isolating and, therefore, grossly inappropriate for defining a service organization. Originating in the self-perceptions of a group, goals tend to promote a competitive stance. The group may see itself as standing against competing groups or institutions, sometimes even those it seeks to serve. A statement of goals has no built-in mechanism for periodic review, criticism, or evolution. When it is adjusted to meet new situations or to take advantage of new technologies, the new set merely takes the place of the old. Worse yet, constantly changing statements of mission or goals lead to a sense of instability, insecurity, and loss of identity. Further, when a library is identified and characterized solely by its goals, it is end-oriented and end-justified. The ends or purposes it serves and how well or how poorly they are met define the institution.

The notion of mission has a problem as well. While a sense of mission is not isolating, as goals are, mission does have an inherently self-referential character that emphasizes the person or group with the mission rather than those it wishes to serve. A larger, transcending vision is needed, one that seeks to identify the intrinsic value of libraries in relation to society and one that will continually inform and correct the mission and goals of a library. The conversation model discussed below may supply the dynamic, organic paradigm needed to bring academic libraries into a more intimate relationship with the central concerns of the educational world.

\section{THE CONVERSATION OF A LIBRARY}

Libraries, if they are true to their original and intrinsic being, seek primarily to collect people and ideas rather than books and to facilitate conversation among peo- ple rather than merely to organize, store, and deliver information. To be sure, libraries have traditionally collected the documents of human imagination and action. In doing so they have preserved the ideas and events of history and have become the centers for ongoing conversations in which people speak their opinions, criticize others', and enlarge or restrict the scope of the discussion. Scholars state their thesis in writing, add information to the topic, argue with each other, and even change the direction of the conversation. The primary task, then, of the academic library is to introduce students to the world of scholarly dialogue that spans both space and time and to provide students with the knowledge and skills they need to tap into conversations on an infinite variety of topics and to participate in the critical inquiry and debate on those issues.

In its earliest meanings conversation meant "living or having one's being in a place or among persons, living together, intercourse, society, intimacy, or engagement with things in the way of . . . study" as well as the "resulting condition of acquaintance or intimacy with a matter. ${ }^{16}$ It had to do with people living with people and sharing intimately their experiences and ideas, their very lives. Conversation was and is an essential activity of human beings and one that informs, critically evaluates, and provides energy and renewal for their life together.

Conversation can be of utmost seriousness as philosophers debate truth, beauty, and justice, world leaders hold a summit meeting, labor and industry meet at the bargaining table, or students prepare for a class session on plate tectonics. Conversation can be purely playful, recreation in the best sense of the word, as friends gather around the fire after a skiing expedition, as the library softball team plans to take on the student intramural champs, or colleagues engage in punning or exchange new jokes. Intercourse, the most intimate expression of communication, wholeness, and integration, reflects the quality and character of conversation, the most general and inclusive activity of human connectedness. 
The preservation of crucial conversations, the first task of libraries, served not only to preserve the record, but more importantly to ensure the continuation of significant conversations already in progress. The intrinsic value of libraries, therefore, is not so much lodged in the collection of information as it is in their relational value. Insofar as libraries make intercourse possible among people and even enter into that intercourse themselves, they are true to their original value. Insofar as they serve to bring people into relationship with each other, they are true to their principal purpose. Conversation, essential to the quality of life of Homo sapiens, provides the occasion and mode for intimate, significant, and ongoing engagement of human beings with each other in society. Libraries bear the critical burden of preserving, facilitating, and participating in those conversations.

Paradigmatic of the original and inherent purpose of libraries, conversation appropriated as the controlling image for librarianship can significantly inform the articulation of mission and goals, collection development policies, services, and the role and character of librarians as well as the organizational structures and procedures of libraries. Adopting the conversational mode may, in fact, provide enduring and powerful direction for all aspects of library service and, in emphasizing participation and process over ends, would provide the internal and ongoing mechanism for evolution and change.

\section{Mission and Goals}

Adopting the promotion of and participation in conversation as the primary task of libraries suggests that librarians searching for suitable missions and goals in the educational setting return to the old notion of vocation or calling. By thinking about calling, one places the focus outside the library and suggests the need to respond to voices other than the library's own. The library and librarians responding to the call of the educational enterprise immediately find themselves in a dynamic, relational stance, not in a passive, isolated one. Discovering the proper voca- tion of the library then becomes an ongoing process of conversation with those involved in teaching and learning, in which resolution of differences and refreshment of purposes can occur.

\section{Collection Development and Services}

Focusing on the enlargement of conversation in the educational environment demands that librarians ask questions about the needs of faculty and students. Which recorded conversations are needed to support the curriculum of this particular institution? What are the impediments to participation in scholarly discussion? What do students need to assist them in becoming active participants in intellectual dialogue? What library services will encourage faculty and student interaction on significant issues? What are the needs of faculty in pursuing their teaching and research? The answers to such questions concerning collection development and services will necessarily come out of continuing conversation with faculty and students, both individually and in the governance structure of the college. Surely the whole range of possibilities-reference service, database searching, term paper consultations, bibliographic instruction, and, one hopes, new possibilities for services not yet envisioned-will be explored in order to bring about the widest participation in the intellectual inquiry.

\section{Bibliographic Instruction}

In the development of citation indexing the conversational paradigm has already influenced entrée to scholarly works. Built on the notion that scholars talk to each other in their writings, citation indexes provide users with access to the contributions of all the participants in a particular discussion through the list of footnotes found in a book or article and through the list of articles and books that subsequently cite the central work.

Pushing the paradigm further, it can significantly inform bibliographic instruction by suggesting that students be invited to discover and participate in discussions that span the globe and the centuries. Using the library, students in the 1980s can enter a dialogue with Plato, Machiavelli, 
and Ghandi on the relationship of the individual to the state. They can participate in conversations on world hunger, euthanasia, and drug abuse. Books, journal articles, and other library materials, understood in their original and proper relationship to each other, represent the opinions and arguments in the ongoing conversations on these issues. The aim of bibliographic instruction becomes one of enabling students to be active and critical in the encounter with other minds. The usual student attempt to assemble a collection of "good quotes" and a lengthy list of references will not do. Furthermore, librarians providing instruction cannot be content with teaching library organization and use of library tools.

The questions for a student become Which conversation do I want to enter? Where and how do I find that conversation? Who are the participants in the discussion thus far? Are there disagreements that I need to know about? How do I assess the value and quality of the various contributions to the conversation and can I make a significant comment on the issue or problem? Instruction, therefore, will include analysis of the problem to discover which conversation a student seeks, instruction on where and how to locate what has been said on the topic, and evaluation of the various contributions to the conversation. Clearly, this includes discovering the qualifications of the participants in the discussion and their particular points of view and assessing their value for the student's particular interest or concern. Bibliographic instruction will encourage and assist students to think critically about the search process, teaching them to use the process itself to refine and narrow a topic and to use the results in the development of their own position on the issue. The proper task of bibliographic instruction becomes teaching critical thinking and enabling participation in intellectual inquiry. The focus is on the process of scholarly dialogue, not on the organization of the library or the production of term papers. The result is that the librarians find themselves intimately engaged with students and faculty as they explore what it means to think critically.

\section{Character and Role of Librarians}

Appropriate library response to the call of the university to pursue critical thinking requires librarians who are educators-library educators, to be sure, whose special and primary task is to facilitate scholarly conversation in the educational environment. Such a role requires librarians who are or can become library and educational generalists, whose critical facilities can be continually honed and sharpened in the dialogue with faculty and students, who are themselves active in the life of the mind and, above all, who relish analysis and examination of significant issues.

A second master's degree in a subject area taught at the college or university is useful for librarians in demonstrating their ability to participate in significant scholarly conversation. More importantly, however, effective bibliographic instruction can best be provided by one who is active in and excited about his or her own research and writing.

Required also will be primary commitment to the educational process, not to the library as an independent entity. Working with faculty as fully professional partners in the pursuit of learning clearly requires professional commitment that is not restricted to forty hours a week, eleven months a year. Neither striving to become faculty members nor content with being custodians of the library, librarians must primarily be concerned with continually seeking and providing library services that will enhance the educational process, that will enlarge participation in intellectual dialogue.

\section{Organizational Considerations}

If librarians are primarily to be promoters of conversation, they must themselves be able to participate fully in the conversations of the library and the university. While it does not dictate any particular form of library organization, providing the context for free and open conversation among the library staff necessarily includes a leveling of hierarchical structures and a loosening of rigid hierarchical control. This is as important for the 
growth of the collection and success of the library in meeting the needs of its users as it is for the growth of individual librarians. Creativity, one suspects, most often comes in the interchange between people and not in individual heads thinking in isolation; individual, intellectual, and, therefore, professional growth occurs most significantly in the agora of free and open debate.

In addition to loosening the bonds of traditional library structures, the barriers of narrow specialization within librarianship need to be broken down. The separation of technical services and reference activities may have been effective and efficient in the past. However, the antipathy, jealousy and competition such division fostered between individuals and departments within the library can no longer be tolerated. The explosion of information that is forcing more careful choice of materials for a particular collection and the radically improved organizing and accessing of materials afforded by computers both underscore the fact that the traditional separation of cataloging and reference is artificial. Librarians intimately involved with faculty and students and with each other in planning and executing library services must be active in and knowledgeable about all aspects of library service.

\section{CONCLUSION}

The conversational mode, intrinsic to the nature of libraries, may provide the paradigm, context, and impetus needed for reconceptualizing academic librarianship. Committed to bringing together, in conversation and dialogue, voices from the past with those of the present, African voices with Spanish and English, young voices with old, men with women, and librarians with faculty, students, and administrators, the academic library will not only provide access to conversations, but will also continually participate in discussion with those it seeks to serve. The extent of the librarians' task, much like the structure of conversation, is open-ended. There is always a great deal more to do; there is much more to say and many more voices to be heard.

\section{REFERENCES AND NOTES}

1. Archibald MacLeish, "The Premise of Meaning," The American Scholar 41:359 (Summer 1972), quoted by Charles Martell, "Myths, Schooling, and the Practice of Librarianship," College \& Research Libraries 45:376 (Sept. 1984).

2. I question Martell's assertion that "Intellectual life centers first in one's own being (ibid., p.377). The life of the mind is nourished and encouraged, first by parents and family. Subsequently it is fed and grows in the encounter with more and more of the world. Intellectual life, it seems to me, cannot occur in isolation; it thrives in interaction with others.

3. Kaye Gapen, "Myths and Realities: University Libraries," College \& Research Libraries 45:356 (Sept. 1984).

4. Willie L. Parson, "User Perspective on a New Paradigm for Librarianship," College \& Research Libraries $45: 370$ (Sept. 1984).

5. Ibid., p.372.

6. The Oxford English Dictionary (Oxford: Clarendon Pr., 1970), V.II-C, p.940. 